\title{
Transformative Adoption of Traditional 'Kantha' Embroidery to Modern Fashion Design Through 'Khadi' Fabric
}

\author{
Md Ahosanul Karim ${ }^{1}$, Md Moniruzzaman ${ }^{1,}$, , Md Eanamul Haque Nizam², Maria Afrin Shammi ${ }^{1}$, \\ Md Tanjibul Hasan ${ }^{1}$
}

${ }^{1}$ Department of Fashion Design \& Technology [FDT], BGMEA University of Fashion \& Technology [BUFT], Dhaka, Bangladesh

${ }^{2}$ Department of Textile Engineering [TE], Bangladesh University of Business \& Technology [BUBT], Dhaka, Bangladesh

\section{Email address:}

ahosanulrana@gmail.com (Md A. Karim), moniruzzamanrasel@buft.edu.bd (Md. Moniruzzaman),

eanamulhaque@bubt.edu.bd (Md E. H. Nizam), mariaafrinshammi@yahoo.com (M. A. Shammi), tanjibulhasan@buft.edu.bd (Md T. Hasan)

${ }^{*}$ Corresponding author

\section{To cite this article:}

Md Ahosanul Karim, Md Moniruzzaman, Md Eanamul Haque Nizam, Maria Afrin Shammi, Md Tanjibul Hasan. Transformative Adoption of Traditional 'Kantha' Embroidery to Modern Fashion Design Through 'Khadi' Fabric. American Journal of Art and Design.

Vol. 6, No. 1, 2021, pp. 6-12. doi: 10.11648/j.ajad.20210601.12

Received: February 6, 2021; Accepted: February 16, 2021; Published: February 26, 2021

\begin{abstract}
For the clothing-based industry, conventional elements' presence in a design increases its demand and acceptance. Nowadays technology plays a vital role in the development of fashion, but it's never the replacement of traditional elements applied to modern fashion design. The author has at first studied the Khadi fabric, Bangladesh from the perspective of its distinctive regional background and social-cultural milieu. Besides the traditional technique, conventional fabric using in the dress design will enhance its morality and aesthetic appearance. The purpose of this study is to explore the traditional Kantha embroidery which will be revitalized through a design process in order to archive its characteristics, heritage, and practice. The results of this study signify a design process from traditional art to modern dress design process through analyzing of mind mapping, mood board, color board, style board, accessories board, fabric swatch, and the final sketch. The outcome of this research will show the transformation of traditional Kanta embroidery which will be adopted by Khadi fabric in order to generate a new trend of the design process in Bangladesh. The author also finalizes the design by ornamenting the surface ornamentations. Finally, the outcome of this study will impact the new upcoming fashion industry and also in the garment industries.
\end{abstract}

Keywords: Transformation, Khadi, Kantha Embroidery, Adoption, Modern Fashion

\section{Introduction}

Tradition \& Culture could be a set of practices, beliefs, values and means of life detained or command by a selected human cluster, that are transferred to them from their intimates through their ancestors, individuals and society around them [1]. Ancient culture could vary from place to put, it should take many forms. At intervals a selected faith it should be the holding and adaptation of some carnivals. At intervals society it should be outlined because the act of behaving in an exceedingly specific means that's being followed over an extended amount of your time. Tradition, Culture and clothing are invincibly certified of a nation [2]. Every culture has the reflection of clothing in its history. As well as every culture has its own existence and creativity in Fashion history. Clothing can be considered as a transmission of information between carrier and recipient through figurative messages in the general or specific scope of dressing culture. Dress is the media to express individual's identity, sentiments, foundation, and articulation of imagination, just as a parity of someone's emotions. In the history of fashion there are such very few fabrics invented which carries freedoms. Khadi is a symbol of struggle for freedom Khadi development was begun by the dad of country, Mahatma Gandhi. It was presented in 1920 as a political weapon for the blacklist of remote merchandise; material specifically and animated a longing for autonomy just as disposition of self-control. This development of khadi 
assembling and weaving began as image of rebellion to demoralize the Indians from wearing the remote garments. Khadi was promoted as an ideology of self-reliance and selfsufficiency. On the other hand, Embroidery is a symbol of a specific tradition and culture. In designing embroidery makes Dreams of excellence utilizing themes commonplace through culture, religion, and condition. Kantha are a symbol of history, culture, family, strength and ingenuity of Bengali tradition (Sreenanda Palit 2018). Kantha embroidery is one of the most seasoned structures that began in Bengal. Kantha embroidery gets its name from a similar word with two unique implications. 'Kantha' signifies 'clothes' in Sanskrit, which mirrors the way that Kantha embroidery is comprised of disposed of articles of clothing or materials. The word also means 'throat' and was named so due its association with the Hindu deity, Lord Shiva. Its starting points can be followed back to the old pre-Vedic ages. Research has been done on Kantha embroidery and freedom of a person's feelings.

\subsection{Overview of Khadi Fabric Characteristics}

Khadi is a fabric that's hand-Owen and is formed from a sort of cotton or silk thread with the assistance of a spinning machine. The spinning machine is called 'charkha'. This dress material is appropriate for each summer and winter seasons [3]. Fabric within the antiquity of Bangladesh is thought to be a serious considers starting our national freelance movement. Khadi is a fabric that mostly came from Asian nation like Bangladesh and Pakistan mainly made of cotton. The material is usually woven from cotton and can to boot embody silk, or wool, that are all spun into yarn on a textile machine called a charkha (Zafar and Bhuiyan, n.d.). It's a versatile material, cool in summer and warmth in winter. Therefore, on enhance the look, textile is typically starched to supply it a stiffer feel. It's wide acknowledged in style circles. Fabric is being advanced in Asian country by material and Village Industries Commission (Zafar and Bhuiyan, n.d.). Khadi throughout the decades has moved from an opportunity warrior's character texture to a design piece of clothing. The present Khadi has numerous faces which are not simply confined to cotton. The exact innovation engaged with the creation of Khadi shifts from district to locale, as do the procedures utilized for its beautification (coloring, weaving, and printing and so on). Today there is such an expanding interest for Khadi that notwithstanding the great many specialists everywhere throughout the nation associated with turning it, they can't fulfill the need from the market. However, it is this highquality nature of the texture with its characteristic deformities that is the magnificence of Khadi. Also, that selectiveness is the thing that the Khadi epicurean aches for consistently. Khadi isn't only a sound monetary recommendation yet additionally a science and a sentiment.

\subsection{Overview of Traditional Kanta Art}

Every nation especially in rural area has their own particular style of embroidery, which joins the way of life, their history and custom [4]. Kantha embroidery includes a basic running line. It is the manner in which the weaving has been utilized that makes it additional normal. It is a run of the mill case of how a straightforward fastens can make expand themes. Generally, the themes are divine beings and goddesses, creatures like duck, fish, peacock; botanical and geometric examples. Kantha weaving is characterized into 'Lepkantha and Sujni Kantha' relying upon the utilization of the completed items in the workmanship. The embroidery fundamentally includes sketching out enriching themes with running fasten, utilizing brilliant strings [5]. There are a couple of precedents that can be used to cover the entire material. Kantha embroidery includes a straightforward running line. It is the way in which the weaving has been used that makes it extra ordinary. It is an average case of how a basic line can make expand themes. Generally, the themes are divine beings and goddesses, creatures like duck fish peacock; flower and geometric examples that mean it very well may be anything the laborer can identify with. It was featured by family unit articles furthermore, other material items can be produced using the created structures by utilizing weaving systems or the created structures can be connected on the beyond of the material by painting, weaving or printing or unmistakable [6].

\section{Research Objectives}

Fashion is upgrading very fast every day, though it has a very good link between previous, present and future. Thus, the present research on Manual Surface Embellishment Techniques on Bangladeshi Traditional Khadi Fabric in modern fashion Era is taken up with following objectives respectively:

a) To find out the traditional Kantha weaving and Minimalistic Line craftsmanship technique.

b) To degree the worthiness of khadi to be utilized as a base material for improvement of garments.

c) To discover style decent variety.

d) To create diverse surface improvement methods with utilizing Kantha embroidery on khadi.

e) To actualize new style by originating surface ornamentation on Khadi the structure will be progressively imaginative.

f) To investigate conceivable outcomes of structuring with customary Kantha embroidery on Khadi texture.

\section{Materials \& Method}

Materials: Pencil (2b, 4b and 6b), art paper, eraser, sharpener, color \& brush for manual sketch of the design, adobe illustrator cs6 \& adobe Photoshop CS6 software.

Methodology: The process of research begins with the selection of a single topic which inspires researcher. From the wide range of ideas belonging to different areas of study a final and inspirational topic is chosen for which the researcher has a fondness. In the context of the study, researcher wanted to carry out a research firstly by making 
sure that have a chance to study history and tradition since researcher personal interest fond of historical subjects. In the field of fashion, the author wanted to study and deeply analyze history of traditional fashion in Bangladesh. The author accepts this subject and reviews numerous blogs, magazines, journals and websites used for the study. Different local and foreign published books and papers have been reviewed in order to make this study authentic and reliable. Different websites helped to reflect historical development and relation to the data embodied in this report.

\section{Background of the Research}

\subsection{Khadi Culture in Bangladesh}

Khadi has a long history in Bangladesh. In the sixth Century, a neighborhood variety of Khadi material was portrayed by Huen Tsang of China and Marco Polo in the twelfth century AD depicts a texture, most presumably Khadi Muslin in the Bengal locale to be fine as the bug catching networks. Romans were incredible devotees of Bengal khadi Muslin and imported immense measures of textures. The khadi weaves of Comilla (south east part of Bangladesh) amid the Mughal time frame were prestigious as profitable materials with unmistakable attributes. Going back to the 12 century A. D. Marco Polo portrayed Khadi of the Bengal district as better than a bug catching networks. The Romans were in like manner amazing admirers of the Bengal Khadi Muslin and in the habit of import phenomenal proportions of surfaces.

\subsection{Khadi Influence in Modern Design}

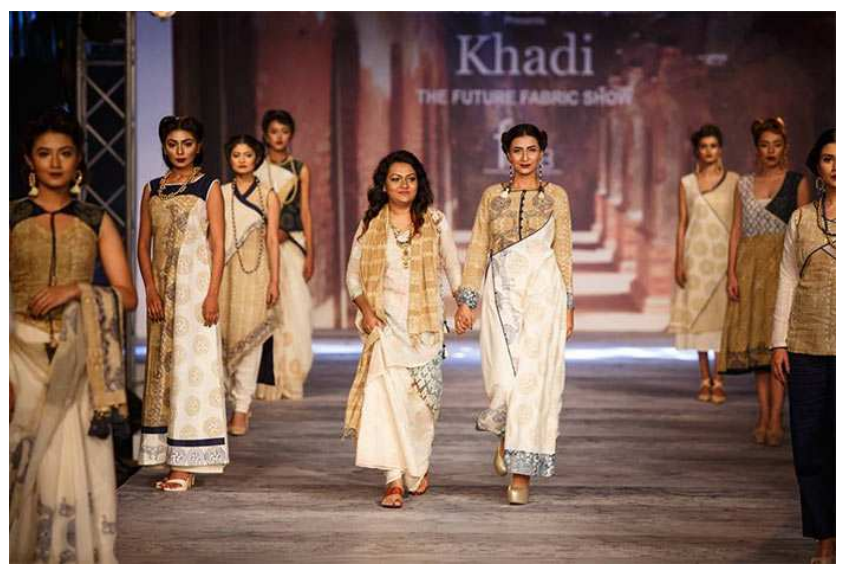

Figure 1. Models are showcasing designer's khadi attires in the Khadi festival 2015.

In 2015, in collaboration with the Cultural Ministry, the Fashion Design Council of Bangladesh (FDCB) officially started the 'Khadi Festival' to uphold this famous heritage. The name 'Khadi: Future Fabric Show' with the 'GOKHADI' tagline is given. From the beginning, this festival has attracted a lot of foreign and local designers (Figure 1). The reason behind its popularity, Khadi has the magical ability to stay cool in summer and warm in winter and is a versatile fabric [7]. Mixed khadi similar to pure khadi, requires less care. The lowest carbon footprint of Khadi textiles can help mitigate global warming to some extent. Weaving the Khadi does not require electricity or fossil fuel combustion. As most of fashion creators are concerned with long-term sustainability, eco-friendliness, and green goods in today's age. Khadi can be a best solution to resolve the natural resource consuming issues.

\subsection{Kanta Influence in Modern desIgn}

Kantha is a form of embroidery that rural women often practice. With soft dhotis and saris, the traditional form of Kantha embroidery was done, with a simple running stitch along the edges [8]. They are known as Lepkantha or Sujni Kantha, depending on the use of the finished product. The embroidered fabric has many uses, including shawls, mirror covers, boxes, and pillows. In some cases, running stitches cover the entire cloth, using beautiful flowers, animal birds and geometric shapes, as well as themes from daily activities [9]. A slightly wrinkled, wavy effect is provided by the stitching on the cloth. Contemporary kantha is applied to a wider range of clothing, mostly using cotton and silk, such as sarees, dupatta, men's and women's shirts, bedding and other furniture fabrics. Kanta usually reflects the traditional art of culture, rural gathering art, motif, symbols, folk art. Generally applied on body suraface, wrist level, chest as well as bottom hem (Figure 2).

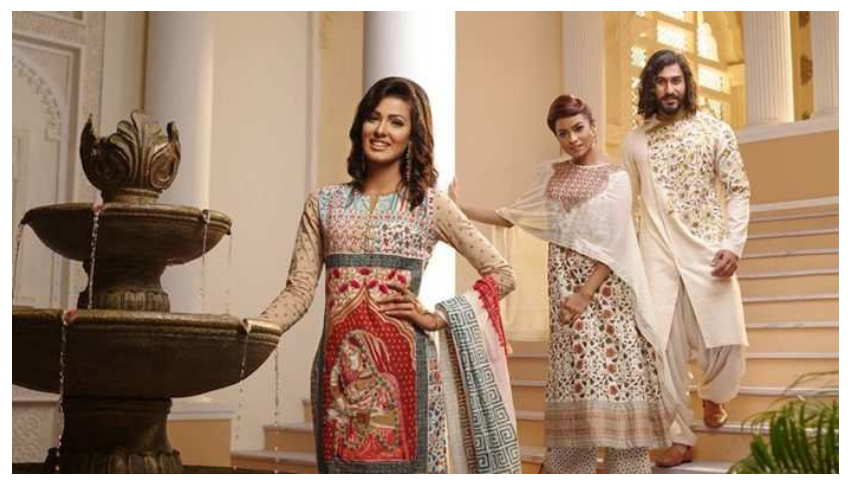

Figure 2. Bangladeshi fashion brand arong collection S/S 2020.

\section{Result \&Discussion}

\subsection{Design Process}

During the design process designer should keep in mind the ecological, sustainable and ethical understanding of fashion in terms of its production, design and consumption ("Slow Fashion Ethics : Memory Abstract Prologue : Ethics of Design" 2009). Concentrating that here the design process will demonstrate a sequence of analyzing state through mind mapping, mood board, style board, color board, fabric swatch board, accessories board and rendered flat sketch. Each state of the analysis reflects the findings of this study. At the end of this process author will illustrate a series of flats ketches design to understand the method and result. 


\subsection{Mind Mapping}

The Mind mapping process has expressed the way of thinking regarding the topic [10]. Initially the keyword that comes to the mind after hearing the theme have been scattered into a frame through creative manner. The elements that will apply and popular related to the creation have been given priority (Figure 3 ).

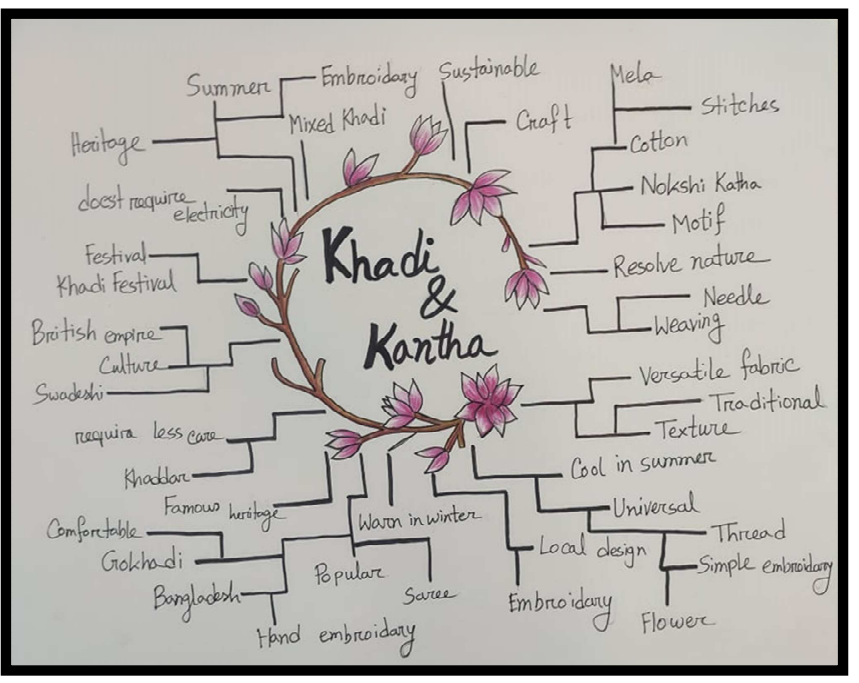

Figure 3. Mind mapping.

\subsection{Story Board}

Sources of inspiration play an important role in the design process, both in defining the context for new designs and in informing the creation of individual designs [11]. The sheets made ought to offer and clear enough about the creation. The motivation behind the fundamental story board is to assemble all that you go over identified with your point and motivation (Figure 4). It fills in as a type of conceptualizing in the making of a design accumulation since it helps in figuring out what you need as a final product.

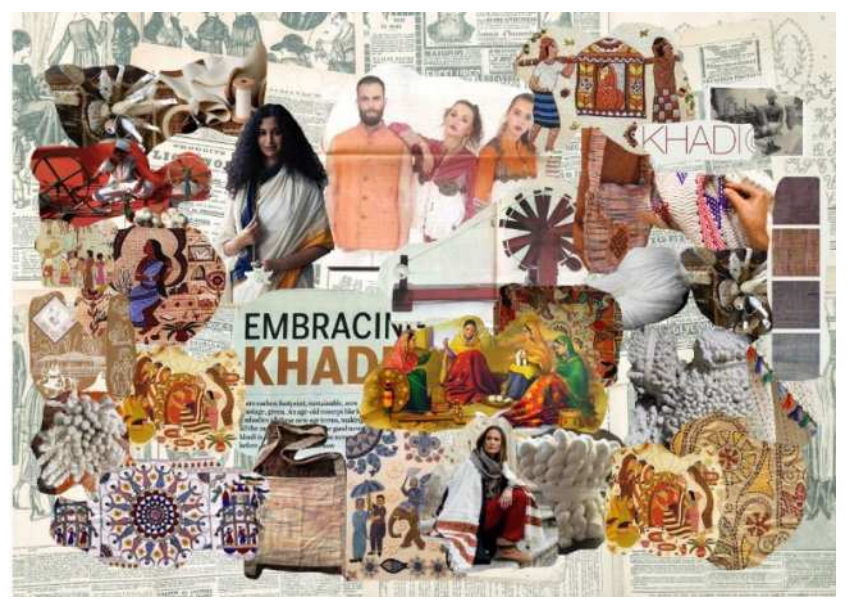

Figure 4. Story board.

\subsection{Style Board}

A style board has been created to show the projected trends of the upcoming seasons of the following years in fashion and textile related industries. This style board helps in defining the scope of the current study that is being carried out. Style board is usually done in all aspects of anticipation related to its construction for instance, color trend, fabric, accessories etc. To be more specific style boards cover it all by providing a list of images or situations and objects the upcoming trends are expected to follow (Figure 5).

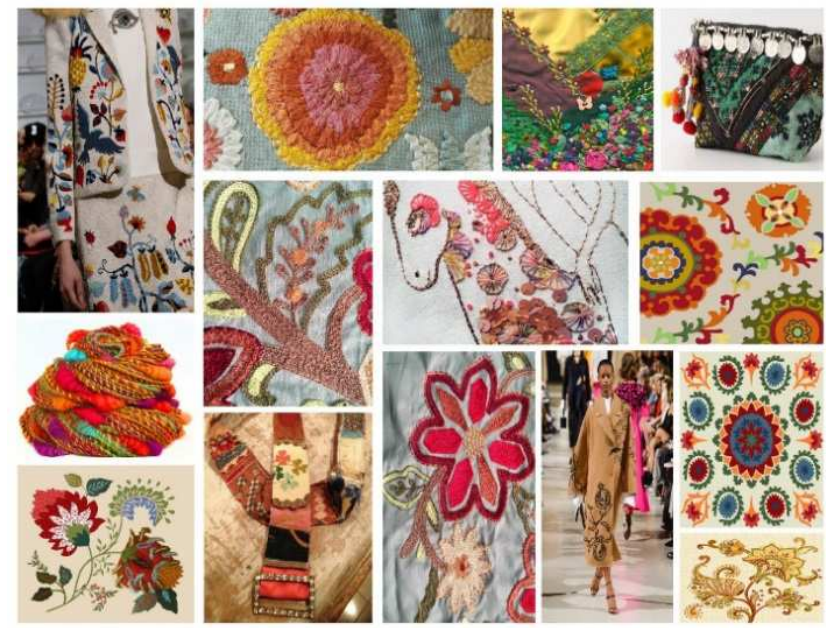

Figure 5. Style board.

\subsection{Accessories Board}

An accessory board is created to show the types of accessories that are expected to be used in the final collection. It can either show the specific elements that are to be used or simply define the aura; for instance, accessories belonging to antique nature can be the aura. An accessory board can be created using actual accessories as well as the pictures (Figure 6). It has to be relevant to the research topic in a specified way rather than generalized.

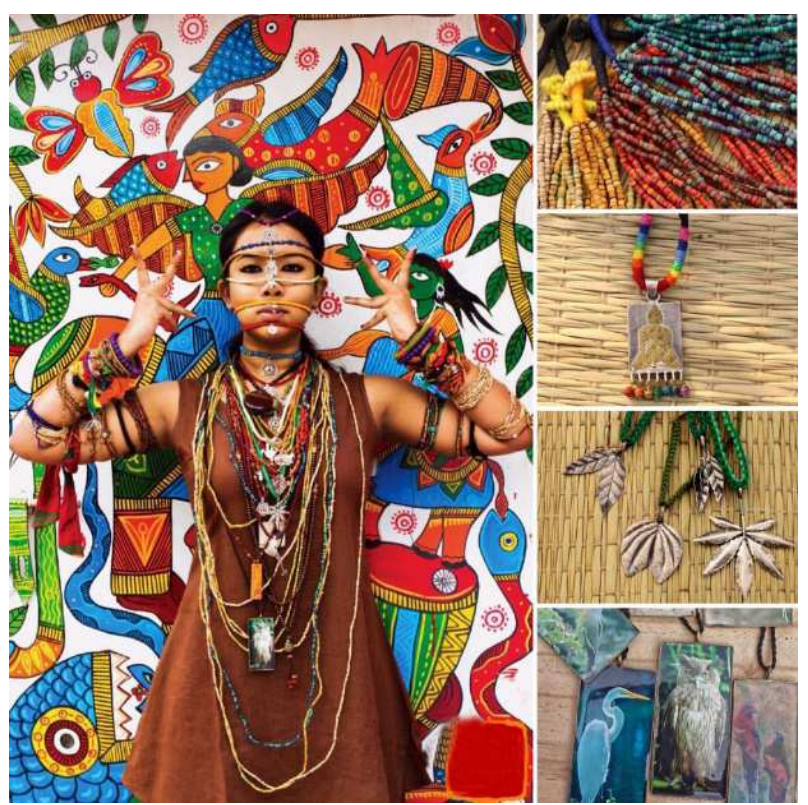

Figure 6. Accessories board. 


\subsection{Fabric Swatch Board}

A swatch board is developed in the wake of a large statistical survey as a method of review. It displays the major used fabric of last five years in fashion industries of Bangladesh and advancement of them also. The board shows the kinds of fabric can be followed to next fashion year (Figure 7). It also depicts the examination's study state of mind.

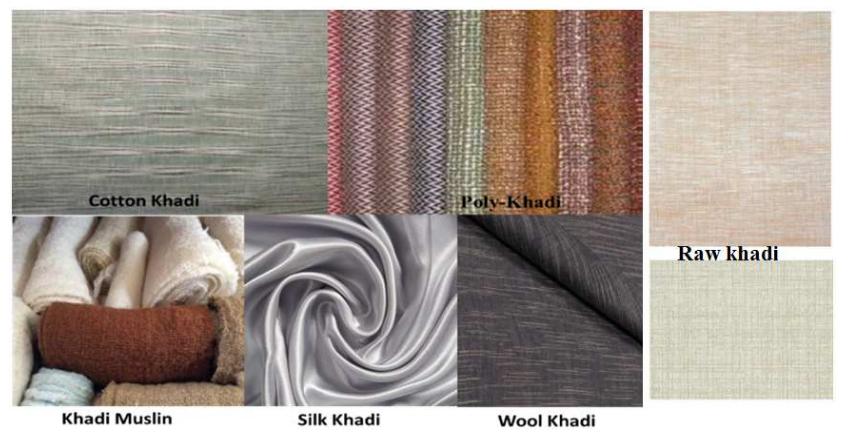

Figure 7. Swatch board.

\subsection{Color Board}

Color forecasting is considered one of the predictions of significant driving forces for textiles and fashion Industry [12]. A basic piece of the discovery is the color board, particularly in the field of structural fashion. No matter how well the outlines are designed, how revolutionary the designs are, an accumulation is nothing if a suitable shading plan is not chosen. Some of the time, due to their ideal color blends or regardless of whether it is played proficiently by solitary shading, the accumulations acquire ubiquity and distinguishing proof. With regard to the topic and motivation of the researcher, the reason for this board is to select ideal shading from the many available alternatives (Figure 8). This board speaks to the color picked explicitly along with pantone and TCX number.

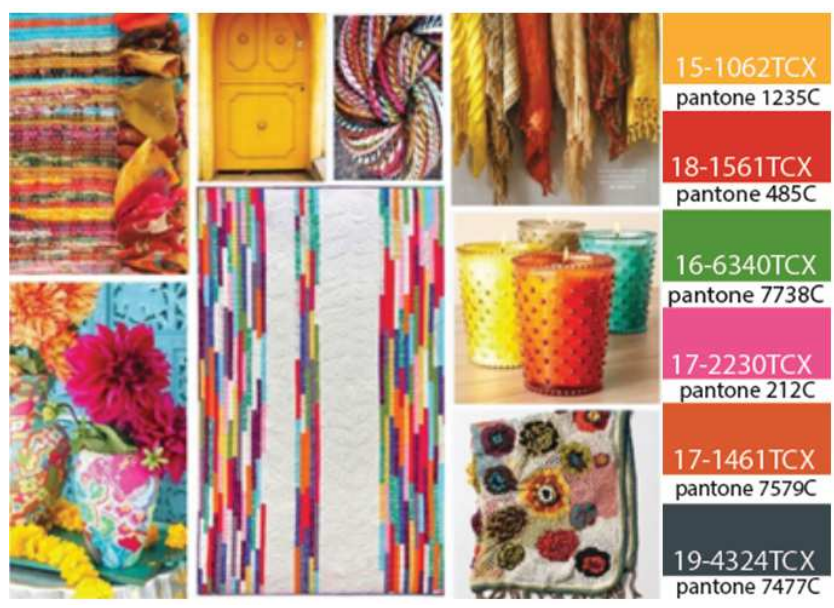

Figure 8. Color board.

\subsection{Mood Board}

The purpose of a mood board is to show the overall sensation of research topic and inspiration. Conceptual mood boards are typically non-product specific and include a range of images creatively representing a theme or idea [13]. It determines the general feeling of research. When the audience gets to know the mood of researcher it helps them with the prediction and imagination for the final product. The set mood for the current research topic is traditional embroidery. The main purpose is to portray your mood and this can also be done by using a single object even for instance if the mood is punctuality a simple object like colorful button or colorful thread embroidery can also be used to create a three-dimensional board (Figure 9). The ideas may vary according to the creativity and aesthetic sense of the researcher.
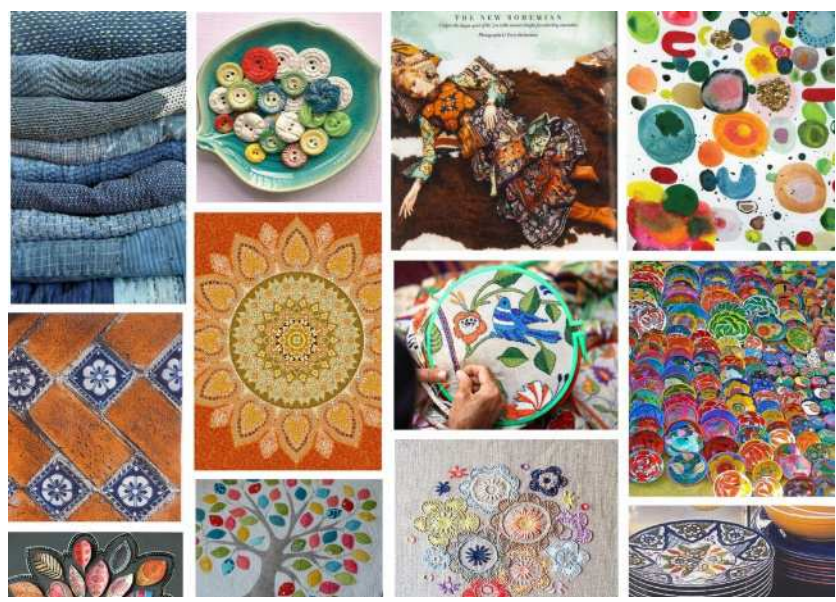

Figure 9. Mood board.

\subsection{Flat Sketch}

After analyzing all above process the authors doing some rough sketches of the costumes belonging to all the categories involved have been created (Figure 10). Below are the four final sketches that were developed in the development stage of the research. A fashion sketch is drawn by fashion designers according to a design theme [14]. Making sure the elements and the silhouettes of the garments are according to the intended mood and theme of the research.

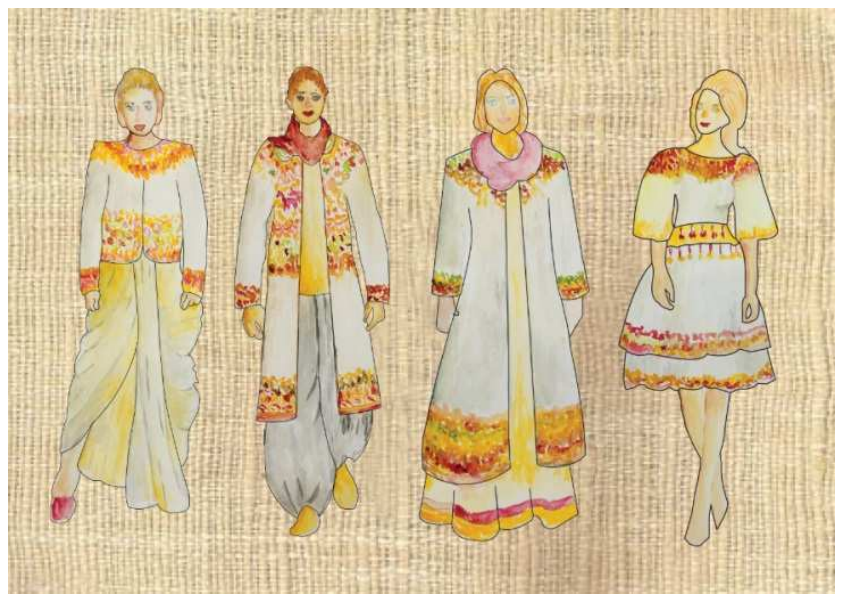

Figure 10. Flat sketch. 


\section{Conclusion}

Fashion is Variable and it's like a cycle. Tradition on fashion is the grate source of inspiration for new design and trend. In modern fashion tradition and culture plays vital role on trend and variation in costume. The usages of the traditional khadi fabric and kantha embroidery with minimalist line art embellishment techniques in modern women's clothing is the objective of this research work which made unique invention by using the surface creation technique. It ought to be remembered that this method of exploiting moderate line workmanship with the kantha embroidery to texturize the piece of clothing surface hasn't been utilized ever of design. Arts and fashion is fewer barriers and each part of the world has its own traditional culture and fashion that we can combine with modern time fashion and come up with a completely unique look to suit the needs of the time. As it doesn't use toxic chemicals, Khadi is organically sustainable. According to these kantha embroidery methods on khadi, to illustrate the religious connotations, a new innovation may be in modern fashion.

\section{Limitation}

This study is intended for further research as a pilot study, and so its initial significance is that it incorporates a draft for the subject study and defines a collection of consignments to be investigated by further research. As this research talk about two different heritage of Bangladesh there have some boundary of observation and analysis. As Bangladesh is a Muslim majority country, traditional art application specially animal or human figure on dresses are being neglected by old people. As the khadi fabric production is not related to advanced machineries, for bulk production it becomes halted. Although Khadi's unique thermal effect lends warmth in winter and makes cool in summer, not applicable for protection of heavy cool weather. The kantha art is too much complex to engrave in khadi through advanced machineries, but hand stitching techniques.

\section{Recommendation}

World fashion has been pushing forward with technology and artificial intelligence in recent years, which could contribute to the neglect of cultural heritage and history [15]. The designers of today are also involved in fusing their culture with modern technology. The author will propose the following issues from all of the above discussion that can be concentrated for inclusive outcomes.

i. Designers should practice with their own cultural elements nationally and globally to signify their heritage.

ii. For overseas or guest learners, there should be unique contextual websites on cultural elements and fashion that are discussed in English. iii. Cultural research has to be emphasized in the academic grade of fashion design.

iv. Designers should travel their own country and source the heritage to revive their worth and authenticity.

v. Fashion brand should establish a corner of their merchandise to emphasis on traditional product visualization.

vi. Government should come forward to generate awareness of the state people towards traditional elements of a culture.

\section{Acknowledgements}

The author would like to offer cordial gratitude to Md. Moniruzzaman \& Maria Afrin Shammi for their everlasting encouragement and support of this research.

\section{References}

[1] Banu, Lisa S. 2009. "Defining the Design Deficit in Bangladesh." Journal of Design History 22 (4): 309-23. https://doi.org/10.1093/jdh/epp046.

[2] Chen, Yugang. 2016. "The Application of Mongolian Costume Elements in Modern Fashion Design," 114-16. https://doi.org/10.2991/msetasse-16.2016.25.

[3] Eckert, Claudia, and Martin Stacey. 2000. "Sources of Inspiration: A Language of Design.” Design Studies 21 (5): 523-38. https://doi.org/10.1016/s0142-694x(00)00022-3.

[4] Freeman, Charles, Sara Marcketti, and Elena Karpova. 2017. "Creativity of Images: Using Digital Consensual Assessment to Evaluate Mood Boards." Fashion and Textiles 4 (1). https://doi.org/10.1186/s40691-017-0102-4.

[5] Hasan, Tanjubul, Maria Afrin Shammi, and Lamia Nasif. 2021. "Comparative Analysis of China (Han) \& Bangladesh Cultural Authentication and Transformation Context on 'Motif Design"” 7 (1): $1-10$. https://doi.org/10.15406/jteft.2021.07.00261.

[6] Jones, Brett D., Chloe Ruff, Jennifer Snyder, Britta Petrich, and Chelsea Koonce. 2012. "The Effects of Mind Mapping Activities on Students' Motivation.” International Journal for the Scholarship of Teaching and Learning 6 (1): 1-21. https://doi.org/10.20429/ijsotl.2012.060105.

[7] Liu, Kaixuan, Xianyi Zeng, Xuyuan Tao, and Pascal Bruniaux. 2019. "Associate Design of Fashion Sketch and Pattern." IEEE Access 7 (c): 48830-37. https://doi.org/10.1109/ACCESS.2019.2906261.

[8] Mandal, Rajiv. 2014. "Ornamental Surface of Nakshi Kantha." Anukriti (An International Refereed Research Journal) An International Refereed Research Journal) 4 (7): 35-38.

[9] Morrell, Anne. 2011. "Kantha: The Embroidered Quilts of Bengal from the Sheldon and Jill Bonovitz Collection and the Stella Kramrisch Collection of the Philadelphia Museum of Art, Darielle Mason (Ed.)." Textile 9 (1): 120-23. https://doi.org/10.2752/175183511x12949158771635.

[10] "Slow Fashion Ethics: Memory Abstract Prologue: Ethics of Design." 2009, 1-12. 
[11] Sreenanda Palit, Dr. Debalina Debnath. 2018. "The Depiction of Socio-Cultural Change through Transformation in Motifs: A Case Study of the Kantha Embroidery of Bengal." Academia. Edu 7 (X): 631-43.

[12] Srivastava, Meenu. 2017. "Khadi: Exploration of Current Market Trend" 4: 439-46.

[13] Walia, Professor Manika. 2016. "A Sustainable Movement Througn Slow Fashion; 'Khadi Cloth and Beyond."' 02nd International Conference on Apparel Textiles and Fashion Design, 1-10.
[14] Wang, Lijing. 2009. "Discussion on Fashion Color Forecasting Researches for Textile and Fashion Industries." Journal of Fiber Bioengineering and Informatics 2 (1): 14-19. https://doi.org/10.3993/jfbi06200902.

[15] Yashraj, Vinayak. 2018. "Emergence of Cultural and Fashion Uniqueness from \&lt;I\&gt;Bihar\&lt;/I\&gt; (India) Rooted in Its Distinctive Regional Background." American Journal of $\begin{array}{llll}\text { Art and Design } 3 & \text { (3): } 26 .\end{array}$ https://doi.org/10.11648/j.ajad.20180303.11. 